\title{
Basic Paths for Coordinated Development of China's Regional Economy and Construction of Long-term Mechanism
}

\author{
Burenmende \\ School of Economics and Management, Inner Mongolia University \\ for the Nationalities, Tongliao, 028000, China
}

\begin{abstract}
Since China's reform and opening-up policy, the market economy drives rapid development of regional economy and promotes comprehensive social progress. However, under the condition of dual economy, the excessive market predatory development results in unbalanced regional economic development; the environmental deterioration and land abuse cause influence on agricultural economic development, and the urban and rural gap is gradually expanded. In order to improve economic development efficiency, China formulates corresponding means from the perspective of national strategy to support coordinated and sustainable development of regional economy. This paper makes an exploration on basic paths for coordinated development of China's regional economy and construction of long-term mechanism.

Key words: regional economy; coordinated development; basic paths; long-term mechanism
\end{abstract}

Under the background of economic globalization, it is very important to handle the relation between economic growth and economic development. As the biggest developing country in the world, China doesn't carry out efficient utilization at the beginning of reform and opening-up due to limited resources, which results in limited economic development; besides, due to China’s low economic technological level and economic management level, China has to implement export-oriented development strategy and depends on import to promote economic development. In particular, since the $18^{\text {th }}$ CPC National Congress, China starts the development strategy of further reform and opening-up; the implementation of economic strategic adjustment 
becomes an important way for change of economic development, and it is the important content of strategic adjustment of current economic structure.

\section{Necessity of coordinated development of China's regional economy}

China has experienced more than 30 years of reform and opening-up; in economic development process, the export-oriented economic development strategy always plays a dominating role. However, with rapid development of Chinese economy, the situation that the extensive economy causes the problems existing in quality of economic development become more and more obvious, which is mainly reflected at expanded gap in regional economy and expanded gap in urban and rural economic income. It is obvious that the export-oriented development pattern lacks the ability if China wants to have continuous and stable development, and China's economic growth level is easily affected by change of external environment. Based on this condition, China has issued a series of policies to promote economic growth from perspective of space to ensure coordinated development of regional economy. Especially after the $18^{\text {th }}$ CPC National Congress, as for regional economic development, China has issued new policies to adjust regional economy, that is, "continue to implement overall strategy of regional development, fully exert the comparative advantage of various regions, and enhance the support on old revolution area, minority area, border area, and poverty-stricken area”. In other words, by use of China's adjustment on future development strategy, while expanding government support, China fully exerts the comparative advantage of market to formulate basic paths for coordinated development of regional economy, and construct a long-term mechanism which will be regarded as the starting point of coordinated development of China's regional economy.

\section{Basic paths for coordinated development of China's regional economy}

(I) The central economic policy shall adapt to the development trend of regional economy.

In terms of China's regional development situation, there is rapid economic development in East China, followed by Central China, and there is a lagged economic development in West China. It is obvious that China's various support 
policies are mainly inclined to eastern coastal area. With expanded gap in China's regional economic income, the relevant research personnel have carried out a research on regional endogenous advantages from perspective of economic development advantage. In terms of policy, it is a practice of respecting economic laws that the state government inclines the preference policy to coastal area, but this practice results in gathering of foreign capital in coastal area and increasingly expanded income gap between eastern coastal area and inland area. This also means that the expansion of China's regional income gap is not caused by policy factor, and has no certain relation with foreign trade, but the result of China's reform and opening-up policy. With production of geography effect, more and more industries and excellent talents will gather in east China, and the scale is continuously expanded, which results in rapid economic growth of east China and increasingly expanded gap between eastern coastal area and inland area.

(II) The enough attention is paid to the coordinated development of global value chain and domestic value chain.

If there exists obvious gap in domestic economic development, it means that China's factor market growth needs to be further perfected. From perspective of economics, the market factors are free-flowing, thus it is able to exert their function in narrowing the gap in regional economic income. However, in China's factor market, there exists the difference in urbanization degree, and there is no innovation on welfare system and household registration system for the purpose of adapting to the demand of social development, which causes expanded regional difference. Due to rapid economic development in east China, more and more production factors gather in east China, but the human resources still stay in original place instead of flowing accordingly. While there lacks of balance between population and production in different regions, the regional income gap happens. This means that it is very necessary to pay high attention to coordinated development of global value chain and domestic value chain. In order to realize a coordinated development of China's regional economy, it is required to establish domestic value chain controlled by domestic enterprises; as the related industries are driven, it is able to promote the coordinated development of 
regional economy and then realize industrial upgrading.

\section{Long-term mechanism for coordinated development of China's regional economy}

Through more than 30 years of reform and opening-up, China has summarized the experience of economic development: while enhancing government's economic coordination force, it is required to adopt market-oriented reform and promote the effective combination between market and government. Especially after China's economic development enters into certain stage, the economic transition is needed; at this time, to only depend on government regulation is not enough. As for market economic development, it is required to regulate economic way in a marker-oriented way and then solve the problems one by one. When it is hard for market regulation to exert its function, various kinds of government regulation mechanisms shall be introduced to exert the macro-control function of government. The " $18^{\text {th }} \mathrm{CPC}$ National Congress" report points out the direction for China's further deep development; in order to continue to step on the development road of socialism with Chinese characteristics and smoothly implement the development strategy of further deepening the reform, China shall insist on the development road of combination of “strong government + strong market”. From perspective of China's realistic development, China shall firstly position "strong government" and determine its functions, and then change original "weak market" to "strong market" to fully exert the function of market guidance, and finally fully exert the regulation function of “strong government” based on strong market while the functions of "strong market" and “strong government" are fully exerted.

(I) To position "strong government" and determine the direction of "strong action"

Based on the fact that China is under transition period of economic growth, the " $18^{\text {th }}$ CPC National Congress" report proposes the concept of “strong government”. However, the so-called “strong government” doesn’t means the “strong intervention” of government on market, but refers to market constructor, server, and guardian rather than intervention on microeconomic things in market, and the strong government plays a dominating role in market operation. It can be seen that the essence meaning 
of "strong government" is "strong service", and it is taken as a scale to practice government conducts so as to respect China's market economy rules. Over a long time, especially under the period of planned economy and transition from planned economy to market economy, in order to drive economy, the government directly participates in China's economic construction and exerts important function. However, with diversified development of economic forms, this way through which the economic development is pushed via government economic pulling not only has low economic efficiency, but also cause slow growth in government fiscal revenue and high local fiscal debts. If the "strong government" wants to take "strong action", it shall change the policy of keeping economic growth via changing government's dominating role, but depend on improving service to exert support function on "strong market”. With the change of government functional organizations, the government finance suffers a bottleneck, thus it is hard to stimulate economic growth via investment. Although the private investment is an important pushing hand of economic development, it is hard to exert its function of true sense due to multiple restrictions, which results in low market investment efficiency. In order to make market environment become active, it is required to optimize market investment and fully utilize the capital of private investment, thus the government shall have "strong actions" in enhancing market economy.

As for government, the government investment shall be made based on objective economic law; as for the infrastructure in favor of regional development, it is required to implement look-ahead investment and expand the scale to form diversified investment system so as to motivate social subject. Furthermore, the look-ahead construction of infrastructure is very necessary in regions with relatively backward economic development; such construction not only can improve the condition of backward regions, but also can adjust the regional conditions and reduce regional cost of enterprises while narrowing the time and space gap so as to narrow the gap of regional economic development.

(II) To seek for "strong market”, and change "weak market” as "strong market” There is especially fierce competition in China's regional economic development, 
with complicated condition. The different resource advantages, different development chances, and the orientation of government support policy will result in the situation that the enterprises seek for the road which conforms to themselves. With formation of diversified economic development trend, the regional economic development will reduce resource cost, production factor cost, and transaction cost; however, in order to realize a continuous development, the market shall adapt to world economic laws and realize trans-regional economic development; this is called "policy-pursuing space expansion”.

In regional development process, a refined division of labor is adopted in order to improve labor efficiency according to regular regulation mode for the purpose of reducing the management cost; however, the more and more refined division of labor will certainly improve transaction cost and then narrow enterprise profit space. At this time, if the enterprises want to obtain higher profit, they shall have enough space to continuously exploit the market, and also adopt trans-regional expansion to make the market become more vigorous, thus the space for enterprises' seeking for survival and development is further expanded. The "strong market” shall be market-oriented and master the initiative of market development. In order to seek for market development, the enterprises will certainly exert their advantages and adopt corresponding measures to expand market share for the purpose of striving to be the "bellwether" in market. Meanwhile, in order to be not defeated by industrial competitors, the enterprises will continuously adjust their survival means; then, in order to obtain first mover advantage, the enterprises will open or find a new path to carry out spatial expansion in different locations.

In order to cultivate enterprises to expand new market space, the government shall simplify administrative procedures, delegate powers to lower levels, and support the enterprises to implement innovation. Under the condition of conforming to central policy, the local government shall implement institutional innovation according to local conditions to reduce enterprises' direct cost and indirect cost, and help enterprises to improve their ability against risks. This means that it is required to establish independent local economy, and take competition as power to make 
enterprises' economic system full of vitality in operation as for China's economic development. In the space of institutional innovation, if the enterprises drive local economic development, China’s social economy will be certainly full of vitality. (III) To exert the regulation function of "strong government" based on strong market The combined pattern of "strong government" and 'strong market” is China's future economic development direction. The so-called "strong government" refers to the situation that the government providers stronger and better service for enterprises and the public. Except for providing enterprises with necessary support and preferential policy, the strong service also include enhancing market supervision order and exerting the strong function on market violation operation. The "strong market" focuses on the perfect market mechanism and perfect operation of market system; it requires to position domestic market and international market to realize further coordination. In this way, even though China's future economic development suffers some frustrations or enters into new transition period, the government can implement effective regulation to make China’s market economy realize smooth development. The economic development pattern of "strong government" and "strong market" can make the government exert certain constraint function on market, and avoid market short-term profit-seeking behavior. The government can have the right to transfer the fund it invests out of short-term profit-making field and then invest to long-term market development environment. The "strong government can keep economic activities, and promote stable economic growth in terms of ecological environmental protection, poverty alleviation and new technology, and new energy development so that the market economy can gradually become mature in macro economic environment. As Landers thinks, the effective allocation of funds is not for maximizing short-term profit, but to conform to long-term profit. The government's macro-control on funds is to ensure correct fund flow, and other works are regulated by the government itself so as to realize effective combination between strong government and market economy.

\section{Conclusion}

In a word, it is very necessary to discuss the basic paths for coordinated development 
of China’s regional economy according to world economic form and current situation of market economic development. Meanwhile, it is also required to construct a scientific and effective long-term mechanism for regional economic development. To construct a pattern of "strong government" and "strong market" becomes the key of China's future development, and the key is to handle the relation between government and market. The market shall have autonomous right and the government shall provide corresponding service. It is required to make clear different functions and different division of labor of "strong government" and "strong market" so that the government can do proper things at proper time instead of excessive intervention on normal market operation; the market shall be operated according to market rules, and take rule of law as standard to promote its efficient operation, and better and quicker development.

\section{References:}

[1] An Husen, Xu Yang: Expansion of Domestic Demand and Coordinated Development of China's Regional Economy under Background of International Financial Crisis [J], Research On Development, 2011 (01).

[2] Jolln Whalley, Ximing Yue. Rural Income Volatility and Inequality in China [J]. National Bureau of Economic Research, 2006.55 (34).

[3] Han Jianyu: Research on Construction of Profit Sharing Mechanism for Coordinated Development of China's Regional Economy [J], Modernization of Management, 2013 (01).

[4] William A. Brock, M. Scott Taylor. The Green Solow model [J]. Journal of Economic Growth, 2010.15 (02).

[5] Peng Rongsheng: Research on Mechanism of Action of Enterprises' Trans-regional Expansion on Coordinated Development of Regional Economy [J], Commercial Research, 2008 (12). 